\title{
Psychometric Properties of the Greek Version of the Children and Youth Physical Self-Perception Profile Questionnaire
}

\author{
Athanasios Kolovelonis ${ }^{1}$, Maria Mousouraki ${ }^{2}$, Marios Goudas ${ }^{1}$, Maria Michalopoulou ${ }^{2}$ \\ ${ }^{1}$ Department of Physical Education and Sport Science, University of Thessaly, Trikala, Greece \\ ${ }^{2}$ Department of Physical Education and Sport Science, Democritus University of Thrace, Komotini, Greece \\ Email: sakisanta@hotmail.com
}

Received July 20 ${ }^{\text {th }}, 2013$; revised August 20 $0^{\text {th }}, 2013$; accepted August $27^{\text {th }}, 2013$

Copyright (C) 2013 Athanasios Kolovelonis et al. This is an open access article distributed under the Creative Commons Attribution License, which permits unrestricted use, distribution, and reproduction in any medium, provided the original work is properly cited.

\begin{abstract}
The aim of this study was to examine the psychometric properties of the Greek version of the Children and Youth Physical Self-Perception Profile questionnaire. The factor structure, internal consistency, temporal stability, concurrent and criterion-related validity, and social desirability effect were examined. Results from the confirmatory factor analyzes supported the six-factor solution and the hypothesized hierarchical structure of these factors. Internal consistency and temporal stability were adequate and no social desirability effect was emerged. Moreover, the concurrent and the criterion validity of the questionnaire were supported. In particular, questionnaire subscales were correlated in expected ways with corresponding subscales of the Harter's Self-Perception Profile for Children as well as with students' scores in shuttle run test and the participation time in sport. Overall, the results showed that the Greek version of the scale is a valid and reliable instrument that can be used to examine Greek children's and youth's selfperceptions.
\end{abstract}

Keywords: Self-Perceptions; Physical Education; Sport; Children and Youth; Questionnaire; CY-PSPP

\section{Introduction}

Self-esteem, which is the feeling that a person has about his or her own value, is associated with psychological health and well-being and has been widely used in explaining human behavior (Fox \& Corbin, 1989). Indeed, the nature of self-perceptions has drawn the attention of research both in academic (Harter, 1982) and in physical education and sport (Fox, 2000) domains.

Recent views have theorized self-esteem as multidimensional and hierarchical in nature. Global self-esteem is located at the apex of this hierarchical model and composed of the combination of people's self-perceptions in different domains (e.g., social, physical, cognitive; Harter, 1982; Marsh, Craven, \& Martin, 2006). For each of these subdomains differentiated selfperceptions may be developed. For example, a student's perceptions about his or her self may be different in academic compared to physical domain.

Physical self-worth (PSW) reflects the general feelings of satisfaction and confidence regarding the self in the physical domain (e.g., sport and physical education). Fox and Corbin (1989) identified four sub-domains of physical self-perceptions, namely sport competence, physical condition, body attractiveness, and physical strength. Sport competence (SPORT) represents students' perceptions regarding their sport and athletic ability, their ability to learn new sport and motor skills, and how confident they feel in sport environments. Physical condition (COND) represents students' perceptions regarding the levels of their physical condition, fitness and stamina, their ability to maintain exercise and how confident they feel in the exercise and fitness setting. Body attractiveness (BODY) represents students' feelings regarding the attractiveness of their bodies and how confident they feel about their appearance. Physical strength (STREN) represents students' perceptions regarding their strength and muscle development, and how confident they feel when they are involved in strength-demanding tasks.

Fox and Corbin (1989) developed the Physical Self-Perception Profile (PSPP) to measure these four physical self-perceptions (i.e., SPORT, COND, BOBY, STREN) adopting a multidimensional and hierarchical approach. The four dimensions of the physical self-perceptions are hierarchically related to more global physical self-perceptions (i.e., PSW) while the global self-esteem or global self-worth (GSW) is located at the apex of this hierarchical model. Fox and Corbin (1989) provided evidence for the psychometric properties of this scale with a college age population. Moreover, results supported the hierarchical structure of the PSPP. In particular, SPORT, COND, BOBY, and STREN scores explained a high percentage of the variance in the overlying construct of PSW which mediated the relationship of these four subdomain subscale scores with global self-esteem.

Whitehead (1995) adopted the PSPP to use it for children and adolescents. The C-PSPP (Whitehead, 1995) consisted of three of the original PSPP (Fox \& Corbin, 1989) subscales (i.e., COND, BOBY, and STREN) and Harter's (1982) sport competence subscale that was almost identical to the corresponding PSPP scale and already validated. Moreover, the C-PSPP included a global PSW (Whitehead \& Corbin, 1991) and a general GSW (Harter, 1982) scale. The exploratory factor analysis 
supported the construct and concurrent validity of the C-PSPP. However, a number of significant cross-loadings were emerged. Further research on the C-PSPP has yield mixed results. In particular, Biddle, Page, Ashford, Jennings, Brooke, and Fox (1993) used British children and youth to examine the psychometric properties of the C-PSPP. The exploratory factor analysis revealed a six-factor solution for the C-PSPP instead of the hypothesized four-factor structure. The psychometric properties of the C-PSPP were also tested in a group of high school athletes (Welk, Corbin, \& Lewis, 1995). Results from the principal component analysis revealed a clear four-factor structure, though cross loadings existed for males on the sport competence scale.

Eklund, Whitehead, and Welk (1997) provided additional support through a confirmatory factor analysis for the factorial validity and the hierarchical structure of the C-PSPP. To avoid misconceptions, because both children and youth participated in their study, Eklund et al. (1997) called the questionnaire the Children and Youth Physical Self-Perception Profile (CYPSPP). More recently, Welk and Eklund (2005) examined the psychometric properties of the CY-PSPP among third to sixth grade elementary students. Confirmatory factor analysis supported the factorial validity and the hierarchical structure of the CY-PSPP model. Moreover, some evidence of invariance between genders was emerged. Convergent and predictive validity were also supported. Similar results regarding the proposed multidimensional and the hierarchical structure of the CY-PSPP model across gender and grades for early adolescents were reported by Hagger, Biddle, and Wang (2005).

Cross-cultural validation of the CY-PSPP was also conducted. Hagger, Ashford, and Stambulova (1998) examined cross-cultural differences in physical self-perceptions in a British and a Russian sample of children and youth. However, the confirmatory factor analyses did not support the hypothesized factor structure of the CY-PSPP although the factor loadings were consistent across national groups. Raustorp, Stahle, Gudasic, Kinnunen, and Mattsson (2005) adopted the CY-PSPP for Swedish children and youth. Result showed good concurrent and content validity of the translated version of the CYPSPP and acceptable test-retest reliability over a 2-week period. However, the factorial validity and the hierarchical structure of the CY-PSPP were not examined in this study. The examination of a Turkish translation of the CY-PSPP (Asci, Eklund, Whitehead, Kirazci, \& Koca, 2005) did not support the six-item per subscale structure of the CY-PSPP model. The use of four items per subscale produced more satisfactory indexes and provided evidence of the hierarchical relationships among these subscales.

The CY-PSPP has been used to examine students' physical self-perceptions in sport and physical education. This research has shown that students' self-perceptions correlated with significant outcomes. In particular, it has been found that physical activity is associated with children and adolescent self-esteem (Fox, 2000). Crocker, Eklund, and Kowalski (2000) found a positive correlation between physical self-perceptions and both boys and girls physical activity levels, although boys were more physically active than girls and had higher perceptions of sport competence and strength. Similar results regarding the positive relationships between physical self-perceptions and participation in physical activities have also been reported (Hagger et al., 1998; Parfitt \& Eston, 2005; Parfitt, Pavey, \& Rowlands, 2009; Raudsepp, Liblik, \& Hannus, 2002; Welk \&
Eklund, 2005). Moreover, students' body mass index was positively correlated with children's self-perception of body attractiveness and physical condition and the $\mathrm{VO}_{2}$ max estimation was positively correlated with children's self-perception of their physical condition (Welk \& Eklund, 2005).

Gender and grade differences in students' self-perceptions have also been reported. Adolescent males tend to report higher physical self-perceptions than their female counterparts (Whitehead \& Corbin, 1997). In particular, boys compared to girls scored higher on physical self-perceptions and in global selfconcept (Hagger et al., 2005; Welk \& Eklund, 2005). Moreover, decreases in self-concept ratings across grades were found although these differences were small in size (Hagger et al., 2005). Moreover, the CY-PSPP distinguishes between children with low and high physical self-perception (Raustorp et al., 2005).

The results presented above highlighted the significant interrelationships between students' self-perceptions and desired outcomes. Thus, examining students' self-perceptions in sport and physical education domains is of great interest. Such research efforts require valid instruments to measure students' physical self-perceptions. Previous findings have shown that CY-PSPP is an instrument that can be used to measure children and youths' self-perceptions. Research evidence supported the factorial validity of the CY-PSPP and its hierarchical structure (Eklund et al., 1997; Hagger et al., 2005; Welk et al., 1995; Welk \& Eklund, 2005; Whitehead, 1995). However, some mixed results (Biddle et al., 1993; Hagger et al., 1998) raise concerns for further examination of the psychometric properties of the CY-PSPP. Actually, the validation process of a questionnaire instrument requires an ongoing work (Fox, 2000). Thus, psychometric properties of the CY-PSPP using different populations should be further scrutinized.

The CY-PSPP was originally constructed and validated for English-speaking children and youth. There is also some evidence from the validation process in non-English speaking samples (Asci et al., 2005; Hagger et al., 1998; Raustorp et al., 2005). However, the results of these studies did not provide a clear picture for the psychometric properties of the CY-PSPP in non-English speaking samples. Raustorp et al. (2005) did not examine the factorial validity and the hierarchical structure of the CY-PSPP while Asci et al. (2005) and Hagger et al. (1998) did not fully support the hypothesized factor structure of the CY-PSPP. Therefore, further examination of the psychometric properties of the CY-PSPP in non-English speaking samples is warranted. Such research will increase our knowledge regarding the utility and generality of this model (Hagger et al., 1998). Furthermore, researchers would have the potential to examine cross-cultural differences in children's and youth' self-perceptions and its relationships with other important outcomes such as human well-being and motivation.

The aim of this study was to examine the psychometric properties of the Greek version of the CY-PSPP questionnaire (factor structure, internal consistency, temporal stability, concurrent validity, criterion-related validity, and social desirability effect) in order to determine whether it is a useful tool for the study of Greek students' physical self-perceptions. It was hypothesized that the Greek version of the CY-PSPP would have a hierarchical structure with a four-factor structure (i.e., SPORT, COND, BOBY, STREN) in the subdomain level, the PSW factor in the domain level, and the GSW at the apex level. In particular, it was expected that SPORT, COND, BOBY, and 
STREN scores would explain a high percentage of the variance of PSW which would mediate the relationship of these subdomain subscale scores with GSW (Hypothesis 1). These factors were expected to have adequate internal consistency and temporal stability (Hypothesis 2) and would not be correlated with students' score in a social desirability scale (Hypothesis 3 ). In terms of concurrent validity, we expected that subscales of the Greek version of the CY-PSPP (i.e., SPORT, BOBY, GSW) would positively correlate with Harter's Self-Perception Profile for Children (SPPC) corresponding subscales (Hypothesis 4). In terms of criterion-related validity, it was hypothesized that students' scores in the shuttle run test and sport participation would correlate in expected ways with subscales of the CYPSPP (Hypothesis 5). Finally, boys were expected to report higher levels of physical self-perceptions compared to girls (Hypothesis 6) and students' self-perception would decrease across the grades (Hypothesis 7).

\section{Method}

\section{Participants}

Two samples with a total number of 239 fifth, sixth, and seventh grade students participated in this study. Sample 1 consisted of 27 students from fifth and sixth grade (12 boys and 15 girls, 2 classes) who completed the CY-PSPP twice with a one week period to test its temporal stability. Sample 2 consisted of 212 students $($ Mage $=11.82$, SDage $=1.21,86$ boys and 125 girls, 1 did not provide gender, 12 classes) from fifth grade $($ Mage $=10.76$, SDage $=.33,25$ boys and 30 girls, 4 classes $)$, sixth grade $($ Mage $=11.72$, SDage $=.33,28$ boys and 49 girls, 4 classes) and seventh grade (Mage $=12.64$, SDage $=1.51,33$ boys and 46 girls, 4 classes). These students came from 3 schools and completed the CY-PSPP to examine its factorial validity by means of confirmatory factor analysis and its structural validity via structural equation modeling. Students from sample 2 participated in additional measurements. In particular, 28 sixth grade students ( 9 boys and 19 girls; 2 classes) completed Harter's (1985) SPPC to examine the concurrent validity, and 16 fifth grade students ( 6 boys and 10 girls; 1 class) performed the shuttle run test to examine criterion-related validity. Finally, 47 students (19 boys and 28 girls) from sixth grade (9 boys and 18 girls; 2 classes) and seventh grade (10 boys and 10 girls; 1 class) completed the social desirability scale to examine the social desirability effect.

\section{Instruments}

\section{Children and Youth Physical Self-Perception Profile (CY-PSPP)}

The CY-PSPP (Whitehead, 1995) measures four subdomains of physical self-worth, namely: sports competence (SPORT), physical conditioning (COND), body attractiveness (BOBY), and physical strength (STREN). Three of these subscales (i.e., COND, BOBY, and STREN) came from the original PSPP (Fox \& Corbin, 1989) while the sport competence subscales came from Harter (1982). Moreover, the CY-PSPP included a global PSW (Whitehead \& Corbin, 1991) and a general GSW (Harter, 1982) scale. Each scale was assessed with six items half of which used reversed scoring. Students responded on 4-point rating scale written in a "structured alternative format". First, students had to decide which of two statements relating to how they feel in specific situations was fit to them and then to indicate whether the statement they selected was "really true for me" or "sort of true for me". Higher scores reflected greater levels of physical self-perceptions.

\section{Self-Perception Profile for Children}

The sport competence, physical appearance, and self-esteem subscales of the Greek version (Makri-Botsari \& Robinson, 1991) of the Self-Perception Profile for Children (SPPC; Harter, 1985) were used. Each subscale consisted of five items which were answered on 4-point rating scale written in a "structured alternative format" using the indicators "really like me" or "sort of like me". The internal consistency (Cronbach's $\alpha$ ) of the three subscales for the present study were $.69, .78$, and .73 , respectively.

\section{The Social Desirability Scale (SDC; Crowne \& Marlowe, 1960)}

This scale consists of 10 items that were responded to an "agree or disagree" format. Six items were positively worded and scored 1 for the agree respond and 0 for the disagree respond, and 4 items were negatively worded and scored 0 for the agree respond and 1 for the disagree respond. Students' scores in SDC scale could range from 0 to 10 .

\section{Shuttle Run Test}

Students' aerobic capacity was evaluated with a shuttle run test (Léger, Mercier, Gadoury, \& Lambert, 1988). Students run back and forth on a $20 \mathrm{~m}$ court touching the $20 \mathrm{~m}$ line at the same time that a sound signal was emitted from a prerecorded tape. Every minute, the frequency of the sound signals increased in such a way that running speed was increased by half kilometer per hour. When a student was no longer able to follow the set pace the test stopped for him or her. The number of successfully completed $20 \mathrm{~m}$ laps was each student's score in shuttle run test.

\section{Sport Participation}

Students responded with a "yes" or "no" the following question: "Do you participate in out-of-school sport activities in sport clubs (e.g., basketball, volleyball, soccer, track and field, swimming, etc.)?" When a student responded "yes" he or she had also to report the time of sport participation in years. This time computed in months was each student's score in sport participation variable. Moreover, students were classified in two groups as either sport participants or non-sport participants.

\section{Procedures}

The CY-PSPP (Whitehead, 1995) items were translated into Greek by the authors and back-translated by two other bilingual persons. The back-translated questionnaire was then compared to the original and minor modifications were applied. The resulting questionnaire was given to 2 fifth grade, 2 sixth grade, and 3 seventh grade students in order to comment about item comprehension. Minor modifications were applied based on these comments. After these minor modifications, the CY-PSPP was given to sample 1 participants twice within one week period to test its temporal stability. Next, the CY-PSPP was given to sample 2 participants to examine the factorial, structural, concurrent, and criterion-related validity of the CY-PSPP, its internal consistency and the social desirability effect. The administration of the CY-PSPP took place in classroom settings 
by two of the authors and two trained assistants. Permission to administer the scale was obtained from the Greek Ministry of Education and Religious Affairs and the school principals. Students participated voluntarily after a parental consent was obtained, they were assured about the confidentiality of their answers and they were told that there was no right or wrong answers. The shuttle run test was conducted during regular physical education lessons by the school physical education teacher and with the assistance of one of the authors.

\section{Statistical Analyses}

Descriptive statistics and correlations among variables were calculated. EQS program (Bentler, 2006; version 6.1 for windows) was used to examine the hypothesized six-factor solution of the CY-PSPP measurement model through a confirmatory factor analysis. Moreover, the hypothesized hierarchical structure among of the CY-PSPP subscales proposed by Fox and Corbin (1989) was examined (Model A; see Hypothesis 1). Two alternatives models were also tested (Sonstroem, Harlow, \& Josephs, 1994). In Model B, in addition to all of the paths hypothesized in Model A, direct paths from SPORT, COND, BOBY, and STREN to GSW were hypothesized. Model C included the all the paths of Model B except of the path from PSW to GSW. The following indices of fit were used: a) the $\chi^{2}$, b) the Nonnormed Fit Index (NNFI), c) the Comparative Fit Index (CFI), and d) the Root Mean Square Error of Approximation (RMSEA). The RMSEA 90\% confidence intervals were also provided. NNFI and CFI values above .90 and .95 are considered to reflect acceptable and excellent fits to the data, respectively (Hoyle \& Panter, 1995; Hu \& Bentler, 1999). RMSEA values of less than .05 and .08 are considered to reflect a close and an acceptable fit, respectively (Browne \& Cudeck, 1993). Considering that the CY-PSPP data in the present study exhibited multivariate kurtosis (Mardia's normalized estimate = 41.03 ) reported values of the fit indices (i.e., $\chi^{2}$, NNFI, CFI, RMSEA) were estimated using the robust method (Bentler, 2006; Satorra \& Bentler, 1994). Finally, a two-way Manova was conducted to examine gender and grade differences in students' scores in the CY-PSPP subscales.

\section{Results}

Descriptive statistics and correlation among variables are presented in Table 1.

\section{Structural Validity}

Confirmatory factor analysis showed an adequate model fit, $\chi^{2}(579, N=205)=764.66, p<.001, \mathrm{NNFI}=.921, \mathrm{CFI}=.927$, RMSEA $=.040$ (90\% CI: .032 - .047) of the six-factor solution of the CY-PSPP measurement model. The CFI and NNFI indexes exceeded the .90 and RMSEA value was below .05 criterions indicating an adequate overall fit of the model to the data. All items loaded on their designated factors (range .49 - .81, average factor loadings: .63). Inter correlations among latent factor were moderate (range: . 20 - .51; Table 1).

Results of the structural analyses supported the hypothesized hierarchical relationship among the CY-PSPP subscales showing that the Model A fit well to the data, $\chi^{2}(583, N=205)=$ $618.72, p=.15, \mathrm{NNFI}=.985, \mathrm{CFI}=.986, \mathrm{RMSEA}=.017$ (90\% CI: .00 - .029). The CFI and NNFI indexes exceeded the .95 and RMSEA value was below .05 criterions indicating an excellent fit of the model to the data. Structural loadings for the subdomain constructs (i.e., SPORT, COND, BOBY, STREN) on PSW were $.38, .42,1.15, .16$, respectively (all significant; $p<.001)$. Moreover, PSW loaded strongly on the $\operatorname{GSW}(.82, p<.001)$.

Two alternatives structural models were also tested. In particular, Model B did not fit well to the data, $\chi^{2}(579, N=205)=$ $1029.72, p<.001, \mathrm{NNFI}=.844, \mathrm{CFI}=.857, \mathrm{RMSEA}=.062$ (90\% CI: .055 - .068). Similarly, the fit of the Model C to the data was inadequate, $\chi^{2}(580, N=205)=1029.77, p<.001$, $\mathrm{NNFI}=.845, \mathrm{CFI}=.857, \mathrm{RMSEA}=.062(90 \% \mathrm{CI}: .055$ $-.068)$.

\section{Internal Consistency and Temporal Stability}

Cronbach's alpha for all CY-PSPP subscales were satisfactory (i.e., SPORT: .76, COND: .79, BOBY: .82, STREN: .76, PSW: .88, GSW: .75). To examine the CY-PSPP temporal sta-

Table 1.

Descriptives and correlations among the variables of the study.

\begin{tabular}{|c|c|c|c|c|c|c|c|c|c|c|c|c|}
\hline & \multicolumn{6}{|c|}{ Descriptives } & \multicolumn{6}{|c|}{ Correlations } \\
\hline & $M$ & $S D$ & 1 & 2 & 3 & 4 & 5 & 6 & 7 & 8 & 9 & 10 \\
\hline 1. CYPSPP-SPORT & 3.03 & .68 & - & & & & & & & & & \\
\hline 2. CYPSPP-COND & 3.18 & .65 & $.36^{*}$ & - & & & & & & & & \\
\hline 3. CYPSPP-BODY & 2.81 & .77 & $.22^{*}$ & $.29^{*}$ & - & & & & & & & \\
\hline 4. CYPSPP-STREN & 2.79 & .64 & $.31^{*}$ & $.30^{*}$ & $.23^{*}$ & - & & & & & & \\
\hline 5. CYPSPP-PSW & 2.96 & .86 & $.23^{*}$ & $.30^{*}$ & $.51^{*}$ & $.26^{*}$ & - & & & & & \\
\hline 6. CYPSPP-GSW & 3.24 & .65 & $.20^{*}$ & $.26^{*}$ & $.31^{*}$ & $.20^{*}$ & $.40^{*}$ & - & & & & \\
\hline 7. SPPC-SC & 3.33 & .56 & $.82^{* *}$ & $.51^{* *}$ & .08 & $.73^{* *}$ & .12 & $.52^{* *}$ & - & & & \\
\hline 8. SPPC-PA & 2.99 & .77 & .03 & .18 & $.60^{* *}$ & .25 & $.69^{* *}$ & $.53^{* *}$ & .15 & - & & \\
\hline 9. SPPC-SE & 3.45 & .53 & $.46^{*}$ & $.44^{*}$ & .32 & $.46^{*}$ & .34 & $.51^{* *}$ & $.54^{* *}$ & $.49^{* *}$ & - & \\
\hline 10. Shuttle Run & 32.94 & 11.28 & $.60^{*}$ & $.63^{*}$ & $.57^{*}$ & $.65^{* *}$ & $.60^{*}$ & $.59^{*}$ & - & - & - & - \\
\hline 11. Sport Participation & 37.88 & 31.87 & .08 & .17 & .08 & $.19^{*}$ & .08 & .13 & $.57^{* *}$ & .12 & .29 & .39 \\
\hline
\end{tabular}

Note: *Significant correlation at .05 level, ${ }^{* *}$ Significant correlation at .01 level. SPPC-SC: Harter's SPPC Sport Competence subscale, SPPC-PA: Harter's SPPC Physical Appearance subscale, SPPC-SE: Harter's SPPC Self-Esteem subscale. 
bility, twenty seven students (Sample 1) completed the questionnaire twice within one week. Intra class correlation coefficients were satisfactory for all CY-PSPP subscales (i.e., SPORT: .78, $p<.001$, COND: .79, $p<.001$, BOBY: .69, $p$ $<.001$, STREN: .86, $p<.001$, PSW: .82, $p<.001$, GSW: .71, $p$ $<.001)$.

\section{Concurrent Validity}

Correlations between the six subscales of the CY-PSPP and the three subscales of Harter's PSPC are presented in Table 1. All correlations were in the expected direction. In particular, the SPORT, BOBY, and GSW subscales of the CY-PSPP were positively correlated with the corresponding subscales of Harter's SPPC ( $r: .82, .60, .51$, respectively).

\section{Criterion-Related Validity}

Correlations between the CY-PSPP subscales and students' score in the shuttle run test and the time participating in sports are presented in Table 1. Students' scores in the shuttle run test were positively correlated with all CY-PSPP subscales while students' sport participation time was positively correlated with STREN (r: .19). Moreover, the one way Manova with sport participation (participants vs non-participants) as independent variable and students scores in the CY-PSPP subscales as the dependent variables, showed a significant multivariate effect, $F$ $(6,187)=2.11, p=.054$, partial $\eta^{2}=.063$. Univariate tests showed that students who participated in sports compared to those who did not participate scored significantly higher in SPORT, $F(1,192)=4.41, p=.037$, partial $\eta^{2}=.022$, in COND, $F(1,192)=5.48, p=.020$, partial $\eta^{2}=.028$, in STREN, $F(1$, $192)=9.50, p=.002$, partial $\eta^{2}=.047$, and in GSW, $F(1,192)$ $=5.87, p=.017$, partial $\eta^{2}=.029$.

\section{Social Desirability Effect}

Correlations between the CY-PSPP subscales (i.e., SPORT, COND, BOBY, STREN, PSW, GSW) and students' scores in the SDS (Crowne \& Marlowe, 1960) were all nonsignificant ( $r$ :.02,.19, -.15,-.10,-.07, -.11, respectively).

\section{Gender and Grade Differences}

To examine potential differences in students' scores in the CY-PSPP subscales across gender and grades, a 2 (gender) $\times 3$ (grade) Manova was conducted. Results showed a significant multivariate main effect for grade, $F(12,388)=2.26, p=.009$, partial $\eta^{2}=.065$. The gender and grade interaction and the main effect for gender were nonsignificant. Univariate tests showed significant differences between three grades in BOBY, $F(2$, $198)=6.53, p=.002$, partial $\eta^{2}=.062$, and PSW, $F(2,198)=$ $3.25, p=.010$, partial $\eta^{2}=.045$. Post hoc analyses showed that fifth grade students scored higher in these two scales compared to seventh grade students.

\section{Discussion}

The aim of this study was to examine key psychometric properties of the Greek version of the CY-PSPP questionnaire. In particular, the factor structure, the internal consistency, the temporal stability, the concurrent and the criterion validity of the CY-PSPP were examined. The present study confirmed the six-factor structure of the CY-PSPP scores as well as the hypothesized hierarchical structure among the subscales of this questionnaire. Moreover, supportive evidence for the internal consistency, the temporal stability, the concurrentand the criterion validity of the CY-PSPP were emerged. Students' scores in the CY-PSPP were not susceptible in the social desirability effect. Therefore, the Greek version of the CY-PSPP had adequate psychometric properties and, thus, can be used in research with Greek students.

More specifically, results from the confirmatory factor analyses supported Hypothesis 1 by showing a clear six-factor solution for the Greek version of the CY-PSPP. Moreover, results supported the hypothesized hierarchical structure of the Greek version of the CY-PSPP. In particular, the four subdomains of the CY-PSPP (i.e., SPORT, COND, BOBY, STREN) were hierarchically related to more global perceptions of physical self-worth and the global self-worth or self-esteem was located at the apex of this hierarchical model. The two alternatives models that hypothesized direct paths from the four subdomains of the CY-PSPP to GSW (Model B) and the elimination of the mediating role of PSW between the four subdomains of the CY-PSPP and the GSW (Model C) was not fit well to the data. Thus, the present findings are consistent with theoretical and empirical evidence regarding the multidimensional and hierarchical structure of physical self-perceptions (Eklund et al., 1997; Fox, 2000; Fox \& Corbin, 1989; Hagger et al., 2005; Welk et al., 1995; Welk \& Eklund, 2005; Whitehead, 1995).

Furthermore, the six subscales of the CY-PSPP had satisfactory internal consistency and found to be stable over a period of one week, supporting Hypothesis 2. Moreover, the CY-PSPP subscales did not correlate with a social desirability scale supporting Hypothesis 3 and showing that students' scores in the CY-PSPP were not susceptible to social desirability effect.

Hypothesis 4 regarding the concurrent validity of the CYPSPP was verified. The subscales of the CY-PSPP correlated in meaningful ways with corresponding subscales of the Harter's (1985) SPPC. In particular, the SPORT, BOBY, and GSW subscales of the CY-PSPP were positively correlated with the corresponding subscales of Harter's SPPC. These findings provided supportive evidence for the concurrent validity of the CY-PSPP, an issue that previous research had not addressed (Eklund et al., 1997; Hagger et al., 2005; Welk et al., 1995; Welk \& Eklund, 2005; Whitehead, 1995).

Results have also supported Hypothesis 5 regarding the criterion-related validity of the CY-PSPP. Several indices to examine the criterion-related validity of the CY-PSPP were used. In particular, students' scores in the shuttle run test were positively correlated with all CY-PSPP subscales. Finally, students' sport participation time was positively correlated $(r: .19)$ with STREN and comparisons between sport participants and nonsport participants revealed that students who participated in sports scored significantly higher in SPORT, COND, STREN, and GSW. However, the size of these differences was relative small. Collectively, all these results are consistent with previous findings (Crocker et al., 2000; Hagger et al., 1998; Welk \& Eklund, 2005) supporting the criterion validity of the CYPSPP.

Contrary to Hypothesis 7, boys and girls reported similar levels of physical self-perceptions. Previous research has shown that boys compared to girls scored higher on physical self-perceptions and global self-concept (Hagger et al., 2005; Welk \& Eklund, 2005). The present findings did not support this result. 
On the other hand, there is evidence to support the structural invariance of physical self-perceptions across gender (Welk \& Eklund, 2005; Hagger et al., 2005). However, in the present study the sample size was relative small to examine this issue. Future research should further explore Greek boys and girls self-perceptions examining the invariance of the CY-PSPP across gender.

Hypothesis 8 was partially supported. Students' self-perception in BOBY and PSW decreased across grades. Fifth grade students reported higher levels of self-perceptions in these two scales compared to seventh grade students. This result is consistent with previous findings that students' scores in self-perceptions decreased across grades (Hagger et al., 2005; Whitehead, 1995). However, in both the present study and the previous ones, these differences were found in some and not all of the CY-PSPP subscales and were relative small in size. Moreover, considering the cross-sectional nature of these comparisons, further examination of the differences in physical selfperceptions across grades using longitudinal designs should be conducted.

Taken together all these results attest to the validity and reliability of the Greek version of the CY-PSPP as well as to its hierarchical structure. Furthermore, the present findings provided evidence for the psychometric properties of the CY-PSPP in non-English speaking students. Previous efforts to validate the CY-PSPP in other cultures were either not fully supportive of the hypothesized factor structure of the CY-PSPP (Asci et al., 2005; Hagger et al., 1998) or they did not examine its factorial and structural validity (e.g., Raustorp et al., 2005). The Greek version of the CY-PSPP showed adequate psychometric properties and, thus, this instrument can be used in research with Greek children and adolescents.

Applications of the Greek version of the CY-PSPP could include the examination of children's and youth's self-perceptions in sport and physical education and the potential correlations of these self-perceptions with other significant outcomes such as physical activity, BMI, sport participation, and psychological well-being. Moreover, cross-cultural differences in children's and youth's physical self-perceptions should be examined and interventions programs to enhance students' selfperceptions can be evaluated through the use of the CY-PSPP. Furthermore, associations between students' self-perceptions and their efforts to self-regulate their learning and performance in sport and physical education should be examined. Recent research in physical education has shown that students can self-regulate their learning and performance with positive results (Goudas, Kolovelonis, \& Dermitzaki, 2013; Kolovelonis, Goudas, Hassandra, \& Dermitzaki, 2012). However, it is has not been examined if physical self-perceptions affect students' efforts to successfully self-regulate their learning and performance.

\section{Limitations}

Limitations of this study should be acknowledged. The sample size did not permit the examination of the gender invariance of the CY-PSPP factor structure. Thus, future research should involve larger samples to examine the invariance of the CYPSPP factor structure across gender and grades (Hagger et al., 2005). Moreover, the examination of the invariance of the CYPSPP factor structure across sport and non-sport participants would increase our knowledge regarding the structure of chil- dren's and youth's physical self-perception in these different populations. Finally, the cross-cultural validation of the CYPSPP should be continued using populations with diverse characteristics from different cultures in order to expand the validity evidence base for this measure.

\section{REFERENCES}

Asci, F. H., Eklund, R. C., Whitehead, J. R., Kirazci, S., \& Koca, C. (2005). Use of the CY-PSPP in other cultures: A preliminary investigation of its factorial validity for Turkish children and youth. Psychology of Sport and Exercise, 6, 33-50.

http://dx.doi.org/10.1016/j.psychsport.2003.10.003

Bentler, P. M. (2006). EQS 6 Structural Equations Program Manual. Encino, CA: Multivariate Software, Inc.

Biddle, S., Page, A., Ashford, B., Jennings, D., Brooke, R., \& Fox, K. (1993). Assessment of children's physical self-perceptions. International Journal of Adolescence and Youth, 4, 93-109. http://dx.doi.org/10.1080/02673843.1993.9747728

Browne, M. W., \& Cudeck, R. (1993). Alternative ways of assessing model fit. In K. A. Bollen \& J. S. Long (Eds.), Testing structural equation model (pp. 136-162). Newbury Park, CA: Sage.

Crocker, P., Eklund, R., \& Kowalski, K. (2000). Children's physical activity and physical self-perceptions. Journal of Sports Sciences, 18, 383-394. http://dx.doi.org/10.1080/02640410050074313

Crowne, D. P., \& Marlowe, D. (1960). A new scale of social desirability independent of psychopathology. Journal of Consulting Psychology, 24, 349-354. http://dx.doi.org/10.1037/h0047358

Eklund, R. C., Whitehead, J. R., \& Welk, G. J. (1997). Validity of the children and youth physical self-perception profile: A confirmatory factor analysis. Research Quarterly for Exercise and Sport, 68, 240256. http://dx.doi.org/10.1080/02701367.1997.10608004

Fox, K. R. (2000). Self-esteem, self-perceptions and exercise. International Journal of Sport Psychology, 31, 228-240.

Fox, K. R., \& Corbin, C. B. (1989). The physical self-perception profile: Development and preliminary validation. Journal of Sport and Exercise Psychology, 11, 408-430.

Goudas, M., Kolovelonis, A., \& Dermitzaki, I. (2013). Implementation of self-regulation interventions in physical education and sports contexts. In Bembenutty, H., Cleary, T., \& Kitsantas, A. (Eds.), Applications of self-regulated learning across diverse disciplines: A tribute to Barry J. Zimmerman (pp. 383-415). Greenwich, CT: Information Age.

Hagger, M., Ashford, B., \& Stambulova, N. (1998). Russian and British children's physical self-perceptions and physical activity participation. Pediatric Exercise Science, 10, 137-152.

Hagger, M. S., Biddle, S., \& Wang, J. (2005). Physical self-concept in adolescence: Generalizability of a multi-dimensional hierarchical model across gender and grade. Educational and Psychological Measurement, 65, 297-322. http://dx.doi.org/10.1177/0013164404272484

Harter, S. (1982). The perceived competence scale for children. Child Development, 53, 87-97. http://dx.doi.org/10.2307/1129640

Harter, S. (1985). Manual for the self-perception profile for children. Denver, CO: University of Denver Press.

Hoyle, R. H., \& Panter, A. T. (1995).Writing about structural equation models. In R. H. Hoyle (Ed.), Structural equation modeling: Concepts, issues, and applications (pp. 158-176). Thousand Oaks, CA: Sage.

Hu, L., \& Bentler, P. M. (1999). Cutoff criteria for fit indexes in covariance structure analysis: Conventional criteria versus new alternatives. Structural Equation Modeling, 6, 1-55. http://dx.doi.org/10.1080/10705519909540118

Kolovelonis, A.,Goudas, M., Hassandra, M., \& Dermitzaki, I. (2012). Self-regulated learning in physical education: Examining the effects of emulative and self-control practice. Psychology of Sport and Exercise, 13, 383-389. http://dx.doi.org/10.1016/j.psychsport.2012.01.005

Léger, L. A., Mercier, D., Gadoury, C., \& Lambert, J. (1988). The 
multistage 20 meter shuttle run test for aerobic fitness. Journal of Sports Sciences, 6, 93-101.

http://dx.doi.org/10.1080/02640418808729800

Makri-Botsari, E., \& Robinson, P. (1991). Harter's self-perception profile for children: A cross-cultural validation in Greece. Evaluation and Research in Education, 5, 135-143. http://dx.doi.org/10.1080/09500799109533305

Marsh, H. W. (1997). The measurement of physical self-concept: A construct validation approach. In K. R. Fox (Ed.), The physical self: From motivation to well-being (pp. 27-58). Champaign, IL: Human Kinetics.

Marsh, H. W., Craven, R. G., \& Martin, A. J. (2006). What is the nature of self-esteem? Unidimensional and multidimensional perspectives. In M. H. Kernis (Ed.), Self-esteem issues and answers: A sourcebook of current perspectives (pp. 16-25). New York: Psychology Press.

Parfitt, G., \& Eston, R. G. (2005). The relationship between children's habitual activity level and psychological well-being. Acta Paediatrica, 94, 1791-1797.

http://dx.doi.org/10.1080/08035250500268266

Parfitt , G., Pavey, T., \& Rowlands, A. V. (2009). Children's physical activity and psychological health: The relevance of intensity. Acta Paediatrica, 98, 1037-1043. http://dx.doi.org/10.1111/j.1651-2227.2009.01255.x

Raudsepp, L., Liblik, R., \& Hannus, A. (2002). Children's and adolescents' physical self-perceptions as related to moderate to vigorous physical activity and physical fitness. Pediatric Exercise Science, 14, 97-106.

Raustorp, A., Stahle, A., Gudasic, H., Kinnunen, A., \& Mattsson, E. (2005). Physical activity and self-perception in school children assessed with the Children and Youth-Physical Self-Perception Profile.
Scandinavian Journal of Medicine and Science in Sports, 15, 126134. http://dx.doi.org/10.1111/j.1600-0838.2004.406.x

Satorra, A., \& Bentler, P. M. (1994). Corrections to test statistics and standard errors in covariance structure analysis. In A. von Eye, \& C. C. Clogg (Eds.), Latent variables analysis: Applications for developmental research (pp. 399-419). Thousand Oaks, CA: Sage.

Slutzky, C. B., \& Simpkins, S. D. (2009). The link between children's sport participation and self-esteem: Exploring the mediating role of sport self-concept. Psychology of Sport and Exercise, 10, 381-389. http://dx.doi.org/10.1016/j.psychsport.2008.09.006

Sonstroem, R. J., Harlow, L. L., \& Josephs, L. (1994). Exercise and self-esteem: Validity of model expansion and exercise associations. Journal of Sport and Exercise Psychology, 16, 29-42.

Welk, G. J., Corbin, C. B., \& Lewis, L. A. (1995).Physical self-perceptions of high school athletes. Pediatric Exercise Science, 7, 152-161.

Welk, G. J., \& Eklund, B. (2005).Validation of the children and youth physical self perceptions profile for young children. Psychology of Sport and Exercise, 6, 51-65. http://dx.doi.org/10.1016/j.psychsport.2003.10.006

Whitehead, J. R. (1995). A study of children's physical self-perceptions using an adapted physical self-perception profile questionnaire. $P e$ diatric Exercise Science, 7, 132-151.

Whitehead, R., \& Corbin, C. B. (1991). Effects of fitness test type, teacher, and gender on exercise intrinsic motivation and physical self-worth. Journal of School Health, 61, 11-16. http://dx.doi.org/10.1111/j.1746-1561.1991.tb07850.x

Whitehead, J. R., \& Corbin, C. B. (1997). Self-esteem in children and youth: The role of sport and physical education. In K. R. Fox (Ed.) The physical self: From motivation to well-being (pp. 175-204). Champaign, IL: Human Kinetics. 